Res Publica. Revista de Historia de las Ideas Políticas ISSN-e: 1989-6115

\title{
El platonismo de Leo Strauss y su recepción neoconservadora*
}

\author{
Sergio Javier Barrionuevo**
}

Recibido: 07 de diciembre de 2018 / Aceptado: 10 de junio de 2019

Resumen. La recepción del pensamiento platónico se torna un elemento clave en el contexto de reconfiguración de "los grandes relatos", en tanto constituye uno de los ejes sobre el cual se estructuran una serie de trabajos en torno a la comprensión de nuestro tiempo. En el presente artículo me propongo mostrar que la recuperación del pensamiento platónico en el marco de los debates políticos contemporáneos establece una desarticulación de la "lógica política platónica". Para ello analizo la rehabilitación del pensamiento platónico por parte de Leo Strauss y su construcción del "platonismo".

Palabras clave: Strauss; platonismo; neoconservadurismo; esoterismo; liberalismo.

\section{[en] Leo Strauss' Platonism and the Neo-conservative Reception}

\begin{abstract}
The reception of Platonic thought becomes a key element in the context of reconfiguration of "great stories", as it is one of the axes on which a series of works are structured around the understanding of our time. In this paper I intend to show that the recovery of Platonic thinking in the context of contemporary political debates establishes a disarticulation of "Platonic political logic". For this, I analyze the rehabilitation of Platonic thinking by Leo Strauss and his construction of "Platonism".

Keywords: Strauss; Platonism; Neoconservatism; Esoterism; Liberalism.
\end{abstract}

Sumario. 1. Platón: ¿filósofo para el presente? 2. Leo Strauss: el platonismo como solución a la "decadencia de Occidente". 2.1. Las acusaciones a Strauss. 2.2. La "filosofía política platónica": la construcción de una tradición. 2.3. Esoterismo. 2.4. La decadencia de Occidente y el liberalismo. 3. La construcción del mito imperialista: El neoconservadurismo norteamericano. 3.1. Neoconservadores. 3.2. Acción política. 3.3. Diagnóstico. 3.4. Fundamentación de la política internacional. 4. Consideraciones finales.

Cómo citar: Barrionuevo, S.J. (2019). El platonismo de Leo Strauss y su recepción neoconservadora, en Res Publica 22.2, 425-443.

* Este artículo fue realizado con el apoyo de una beca doctoral de CONICET y fue elaborado en el marco del Proyecto UBACyT 2013-2016 (Código: 20020120100073), dirigido por Julián Gallego y Carlos García Mac Gaw (Universidad de Buenos Aires, Argentina). También está vinculado a las actividades desarrolladas en los Proyectos ICI-UNGS 2015-2016 (Código: 30/1109), dirigido por Marta Madero y Eleonora Dell'Elicine (Universidad Nacional de General Sarmiento, Argentina) y PICT-2015-2064 (Res. 240/16), dirigido por Diego Paiaro (ANPCT, Argentina). Agradezco, además, al prof. Dr. Pedro López Barja de Quiroga (Universidad de Santiago de Compostela, España) los comentarios y objeciones realizadas a una versión preliminar de este trabajo que me permitieron repensar algunas cuestiones descuidadas en esa versión. No puedo dejar de agradecer también a David Sibio (Universidad Nacional de General Sarmiento, Argentina) la lectura atenta y los comentarios a los borradores de la última versión.

** Universidad de Buenos Aires, Argentina sjbarrionuevo@gmail.com 
El siglo XX se presenta como un siglo de grandes interpretaciones. El "giro hermenéutico" llevado a cabo durante dicho siglo proporciona herramientas para la elaboración de nuevas interpretaciones. Sin embargo, tras el "fin de los grandes relatos" sentenciado por el posmodernismo", pareciera ser que ya no hay lugar para los modelos de interpretación de larga duración. Hacia fines del siglo pasado y en los comienzos del siglo XXI se puede observar que la sentencia posmoderna funciona más como anhelo que como descripción de una situación. Los Estados modernos no sólo no abandonaron los mecanismos retóricos de legitimación narrativa propios del siglo XIX ${ }^{2}$ y vinculados al "proyecto de la modernidad", sino que fueron mutando hacia formas complejas de fundamentación de las políticas de Estado. Por este motivo, el estudio de dichas narraciones y las trayectorias construidas en ellos se vuelve un elemento central en la comprensión histórica de nuestro tiempo.

La recepción del pensamiento platónico se torna clave en dicha coyuntura. Esta constituye uno de los ejes sobre el cual se estructuran una serie de trabajos que pretenden la comprensión de nuestro tiempo. Por esta razón, en el presente artículo me propongo mostrar que la recuperación del pensamiento platónico, en el marco de los debates políticos contemporáneos, establece una desarticulación de la lógica política platónica. Por ello, en primer lugar, expongo los alcances de las lecturas contemporáneas sobre Platón como filósofo para el presente (Karl Popper y Leo Strauss). En segundo lugar, me detengo en una de estas propuestas: la rehabilitación del pensamiento platónico por parte de Leo Strauss y su construcción del "platonismo". Luego, analizo los alcances del valor positivo del platonismo propuesto de Strauss a partir de la recepción y aplicación política de su pensamiento por parte del neoconservadurismo norteamericano. Finalmente, realizo unas consideraciones finales acerca de la transposición del pensamiento platónico en la clave del imperialismo norteamericano.

\section{Platón: ¿filósofo para el presente?}

Platón como filósofo del presente es un hecho ineludible. Ya sea que tomemos el genitivo en su función objetiva y concibamos el "presente" como el objeto sobre el cual Platón dirige su pensamiento, o bien en su función subjetiva y consideremos su condición de filósofo como producto de su tiempo. Martín Heidegger sostenía "todo lo grave $d a$ que pensar"4; de forma tal que, siguiendo este dictum podemos afirmar que Platón es un "pensador" de su presente en tanto asume la tarea de pensar "lo grave" (Bedenkliche) de su tiempo ${ }^{5}$. Puesto que tanto su obra metafísica como la política pueden ser leídas en esta clave.

Sobre este punto ver el trabajo clásico sobre esta cuestión: J.-F. Lyotard, La condición posmoderna [1969], Madrid, REI, 1989, pp. 63-71.

2 Cf. H. White, Metahistoria. La imaginación histórica en la Europa del siglo XIX, Buenos Aires, Fondo de Cultura Económica, 2010, pp. 257-268.

3 Cf. R. Cristin, "Razón y subjetividad después del posmodernismo. Hacia una hermenéutica de lo moderno como proyecto infinito", en R. Cristin (comp.), Razón y subjetividad. Después del posmodernismo, Buenos Aires, Almagesto, 1998, pp. 193-201.

4 M. Heidegger, Was heisst Denken?, en Gesamtausgabe, I. Abteilung: Veröfflentichte Schriften 1910-1976, Band 8 (GA 8), Frankfurt am Main, Vittorio Klosterman, 2002, p. 6 (trad. del autor).

5 Sobre este punto ver A. Poratti, Platón, Fedro, Madrid, Akal, 2010, pp. 15-20, quien concibe a Platón justamente como un "pensador de crisis". 
Durante el siglo XX, en cambio, muchos filósofos, historiadores y teóricos políticos han tratado de releer a Platón con vistas de encontrar en él alguna clave para entender nuestro presente. Sin embargo, en el recorrido los senderos se bifurcan. Por un lado, se creyó encontrar en dicho pensamiento el origen de "los males" de nuestro tiempo; mientras, por otra parte, se trató de recuperarlo como un modelo de pensamiento capaz de portar elementos para repensar dichos "males". Entre los primeros, podríamos ubicar el libro de Karl Popper The Open Society and its Enemies (1945), quien encuentra en el pensamiento platónico el origen de la fundamentación del totalitarismo ${ }^{6}$. Mientras que, entre los segundos, podemos ubicar lecturas como la de Leo Strauss principalmente en sus libros Natural Right and History (1954), The City and Man (1964) y The Argument and the Action of Plato's "Laws" (1975), quien considera la filosofía de Platón tanto un análisis de los problemas que afectan a la pólis - el relativismo y la inconsistencia del régimen democrático- como una propuesta de solución - el gobierno de los sabios-. Éste último considera que el pensamiento de filósofo ateniense puede dar una respuesta para los problemas del Estado moderno ${ }^{7}$.

Los libros de Popper y Strauss se enmarcan en contextos de producción diferentes y, por tanto, también constituyen proyectos diferentes. Karl Popper, judío vienés exiliado en Nueva Zelanda tras la toma del poder por parte de los partidarios de Hitler en Viena, escribe su libro durante su exilio en el marco de la Segunda Guerra Mundial y el advenimiento de los Estados totalitarios en Europa, realizando uno de los principales aportes del pensamiento político liberal contra el totalitarismo. Si bien luego sería reconocido internacionalmente por sus aportes en el campo de la epistemología clásica, en el momento que publica The Open Society era un autor ignoto en lengua inglesa ${ }^{8}$. Sin embargo, el contexto queda inscripto en el prólogo de la obra, donde Popper plantea el objetivo de su libro: "contribuir en nuestra comprensión del totalitarismo y al significado de la lucha permanente contra él". En una reconstrucción posterior de su biografía intelectual afirma que "The Poverty y The Open Society fueron mis esfuerzos de guerra" ${ }^{\prime \prime}$. Mientras que Strauss, judío alemán nacido en 1899 que tuvo que emigrar hacia 1932 para radicarse definitivamente en Estados Unidos desde 1937, a pesar de haber trabajado en prestigiosas universidades norteamericanas y de publicar obras de referencia en el campo de filosofía política,

6 Cf. K. Popper, The Open Society and its Enemies, 2 vols., London, Routledge, 1945, I, p. 74-105. No obstante, desde una perspectiva genealógica F. Nietzsche, Götzen-Dämmerung, oder: Wie man mit dem Hammer philosophirt. En Sämtliche Werke, ed. G. Colli \& M. Montinari, Kritische Studienausgabe, Band 6 (KSA 6), Berlin, De Gruyter, 1999, pp. 80-81, había encontrado también en Platón el origen de "los males" de Occidente. Sin embargo, ambos autores difieren en la cualidad de dichos "males", mientras para Popper es el ataque a los fundamentos de la democracia liberal, para Nietzsche es la fundamentación onto-teológica de la realidad con la cual comienza la "historia de un error" (Geschichte eines Irrthums): el dualismo entre mundo verdadero y mundo aparente.

7 Cf. L. Strauss, The Argument and the Action of Plato's "Laws", Chicago and London, The University of Chicago Press, 1975.

8 Tal es así que el libro no consigue editor en Estados Unidos y es publicado por la editorial Routledge de Londres. En la fecha de publicación de ésta obra, 1945, Popper ya había escrito en alemán su libro seminal en el campo de la epistemología: Logik der Forschung, Berlin, Springer Verlag, 1935. Sin embargo, esta obra fue reescrita para su publicación inglesa bajo el título The Logic of Scientific Discovery, London, Hutchinson \& CO, 1959, la cual le daría a Popper la fama y el reconocimiento académico a nivel mundial.

$9 \quad$ K. Popper, The Open Society..., op. cit., p. 1 (trad. propia).

10 K. Popper, Unended Quest: An Intellectual Autobiography, London-New York, Routledge, 1994, p. 131 (trad. propia). 
no era una figura central en el mundo académico norteamericano. Sin embargo, logró establecer un núcleo de discípulos y entrar en discusión con notables intelectuales de la época como Alexandre Kojève ${ }^{11}$ y Hans-Georg Gadamer ${ }^{12}$. En su libro Natural Right and History (1953) realiza un diagnóstico del contexto en el que escribe: "el rechazo contemporáneo del derecho natural conduce al nihilismo. No, es idéntico al nihilismo"13. Esto, para Strauss, al igual que para Popper $^{14}$, significa una época de relativismo moral. Contra ello propone estudiar el pensamiento político clásico, en tanto "nos vemos obligados a hacerlo por la crisis de nuestro tiempo, la crisis de Occidente" 15 . Por esta razón, mientras uno estudia el pensamiento platónico en busca de comprender el fundamento del pensamiento totalitario, el otro en cambio lo hace para encontrar una clave que permita superar el relativismo moderno.

La lectura de Popper inscribe a Platón en lo que él define como "historicismo", el cual se caracteriza por entender el desarrollo histórico sobre la base de la "doctrina del pueblo elegido"16. Para éste el pensamiento platónico se incluye en esta tradición en tanto establece la estricta división en clases (gobernantes y gobernados), la identificación del destino del Estado con el de la clase dirigente, el monopolio de las virtudes por parte de esta clase, la censura de las actividades intelectuales y la autarquía del Estado ${ }^{17}$. No obstante, para Popper, el carácter totalitario de este pensamiento reside en su fundamento ontológico: la teoría de las Formas. Al colocar "la Justicia" como aquello que regula el funcionamiento de la pólis ideal y, además, al ser ésta una Forma funciona como elemento que elimina la posibilidad de todo cambio político, en tanto responde al Estado original fundado en la naturaleza humana ${ }^{18}$. Lo que tiene en común el "historicismo" semítico y el platónico en la lectura de Popper es el carácter mesiánico de su concepción de la historia, ambos se sostienen sobre la "lógica del destino"; sin embargo, lo que los distancia es su definición del "sujeto elegido". Mientras los primeros ubican en ese lugar al pueblo hebreo, el segundo coloca allí a la aristocracia gobernante, pero ambos utilizan argumentos naturalistas.

Leo Strauss, sostiene Melissa Lane, comparte el rechazo a cierto tipo de "historicismo" que considera peligroso cuando esconde bajo dicha forma algún tipo de dogmatismo ${ }^{19}$. Puesto que éste tipo de historicismo atentaría contra la razón. Sin

11 Cf. L. Strauss \& A. Kojève, On tyranny (including the Strauss-Kojève correspondence), Chicago, University of Chicago Press, 2000.

12 Cf. G. E. Tucker, "Correspondence Concerning Wharheit und Methode: Leo Strauss and Hans-Georg Gadamer”, en Independent Journal of Philosophy, 1978, pp. 5-12.

13 L. Strauss, Natural Right and History, Chicago and London, The University of Chicago Press, 1953 , p. 5 (trad. propia).

14 Cf. K. Popper, Unended Quest, op. cit., p. 133, sostenía que "one of the main arguments of The Open Society is directed against moral relativism".

15 L. Strauss, The City and Man, New York and Chicago, The University of Chicago Press, 1964, p. 1 (trad. propia).

16 K. Popper, The Open Society..., op. cit., p. 6-8.

17 Cf. ibidem., p. 74.

18 Cf. K. Popper, The Open Society..., op. cit., p. 77-81. C. Arruzza, "«Cleaning the City»: Plato and Popper on Political Change”, Polis 29 (2), 2012, pp. 259-285, aquí p. 276-285, ha criticado esta lectura de Popper, proponiendo una lectura diferente sobre la cuestión de la posibilidad del cambio politico, ante lo cual argumenta que la construcción utópica de Platón aportaría mejores herramientas que el modelo popperiano. M. Lane, "Plato, Popper, Strauss, and Utopianism: Open Secrets?”, History of Philosophy Quarterly 16 (2), 1999, pp. 119-1, aquí pp. 129-135, por su parte, rechaza la intrepretación popperiana del historicismo, el holismo y la felicidad en Paltón.

19 "We are forced to suspect that history is the guise in which dogmatism likes to appear in our age", L. Strauss, Natural Right and History, op. cit., p. 2. Cf. M. Lane, op. cit., p. 119-120. 
embargo, por otra parte, busca recuperar la tradición del historicismo semítico como matriz de Occidente, el cual no es calificado de modo negativo debido a que propone una "religión de la razón". En este sentido, sostiene que:

El judaísmo ha enseñado a la humanidad la religión de la razón. [...] Necesitó la ayuda de la filosofía platónica y, sobre todo, de la filosofía kantiana para liberarse completamente de la irrelevancia mítica y de otro tipo. Pero esta ayuda simplemente permitió al judaísmo actualizar plenamente lo que intentaba ser desde el principio y lo que fue esencialmente en todo momento ${ }^{20}$.

Su lectura de Platón, por tanto, también propone incorporarlo en la tradición del "historicismo", aunque, contra Popper, ésta sería una de las virtudes del pensamiento platónico.

No obstante, la oposición entre Popper y Strauss no es una mera reconstrucción del contexto intelectual de dos obras de la primera mitad del siglo XX, sino que efectivamente ambos se encontraron enfrentados personalmente a causa de ellas. En la década de los cincuenta, cuando Popper estuvo en Harvard dando una conferencia en las prestigiosas "William James Lectures", dio también una charla en la Universidad de Chicago, donde Strauss tuvo la oportunidad de escucharlo. Luego de escuchar la charla éste escribe una carta a Eric Vogelin a quien le manifiesta que la charla "fue muy mala,... el positivismo más perdido y sin vida" ${ }^{21}$. Por ello le pide su opinión, ante lo cual Vogelin le responde que Popper es "un peleador en el plano de la ideológico bastante primitivo" y que su libro The Open Society es "insolente, una estupidez diletante. Cada oración es un escándalo..."22. A partir de ésta respuesta el propio Strauss comenzó una campaña contra la contratación de Popper en Estados Unidos por intermedio de Kurt Riezler, un diplomático alemán que había conocido en la "New School of Social Research of New York", quien ejercía una notable influencia en el ámbito político-académico estadounidense.

A pesar del influjo que ejerció la obra de Popper en los ámbitos académicos y de discusión política ${ }^{23}$, la obra de Strauss adquirió una mayor presencia en las últimas décadas debido a las controversias en torno a su influencia y, por tanto, su supuesta responsabilidad por transitividad en la fundamentación de la política internacional norteamericana. Esta influencia se derivaría de la aplicación de la filosofía platónica elaborada por Strauss en el contexto del conflicto internacional contra el terrorismo en medio oriente.

\section{Leo Strauss: el platonismo como solución a la "decadencia de Occidente"}

Los intentos de restituir a Platón como filósofo para el presente establecen nuevos temas en la agenda teórico-política. La recuperación y reconfiguración de la filosofía

20 L. Strauss, "Introduction Essay for Herman Cohen, Religion of Reason out of the Sources of Judaism", en Studies in Platonic Political Philosophy, Chicago and London, The University of Chicago Press, 1983, p. 234.

$21 \quad$ P. Emberly \& B. Cooper (eds.), Faith and Political Philosophy: The Comspondence Between Leo Strauss and Eric Voegelin, 1934-1964, University Park, The Pennsylvania State University Press, 1993, p. 67.

22 Ibidem.

23 Cf. I. Jarvie \& S. Pralong, "Introduction”, en I. Jarvie \& S. Pralong (eds.), Popper's Open Society After Fifty Years. The Continuing relevance of Karl Popper, London-New York, Routledge, 1999, pp. 2-15. 
política straussiana por parte de los "neoconservadores" norteamericanos, así como la base platónica de dicha filosofía política, ha dado lugar a revisitar en la actualidad no solamente a los pensadores políticos contemporáneos sino también a sus fuentes. En este contexto, la línea de interpretación straussiana rehabilita al pensamiento platónico en los debates contemporáneos. No obstante, dicha "rehabilitación" no puede realizarse sin más, sino que exige procesos de traducción y reconfiguración de las lógicas en las cuales los conceptos platónicos se inscriben y adquieren sentido. En consecuencia, en este apartado propongo un recorrido de dicha agenda teórico-política platónica en el marco de su recuperación contemporánea por parte de Leo Strauss.

\subsection{Las acusaciones a Strauss}

El punto de partida de la popularización de las acusaciones contra Strauss se podría ubicar en la publicación del libro de Allan Bloom, The Closing of the American Mind (1987). Este libro presenta un análisis sobre la decadencia del sistema educativo norteamericano desde una perspectiva política straussiana, a pesar de que prácticamente no lo menciona en la obra ${ }^{24}$. La popularidad que adquirió el libro colocó a los straussianos y, por consiguiente, a Strauss en el centro de la discusión política estadounidense. No obstante, las críticas no tardaron en llegar ${ }^{25}$. Uno de los textos que coloca a los straussianos en el centro de la disputa es el artículo de Gabriel Almond "Separate tables: Schools and sects in political science". En este texto Almond acusaba a una serie de publicaciones, provenientes de este prominente grupo, de constituir un ghetto que se cierra sobre sí mismo debido al uso de una jerga, la cual define su retórica de manera críptica ${ }^{26}$. Sin embargo, Shadia Drury en un artículo previo al libro de Bloom ${ }^{27}$, ya había puesto el acento en los modos de leer y desarticular el hermetismo straussiano ${ }^{28}$.

Drury, partiendo de una clave de lectura esotérica del pensamiento de Strauss, concluye que su obra no establece un análisis de "historia de las ideas". Por este motivo, considera que se lo debe tomar como un modelo de propuesta de ideas políticas con un carácter claramente conservador. Para ella la lectura establecida en Persecution and the Art of Writing (1952) ${ }^{29}$ para los filósofos clásicos inscribe en el análisis

24 Strauss sólo es citado en un pasaje de la obra (A. Bloom, The Closing of the American Mind, New York, Simon and Schuster, 1987, p. 167) en el contexto del análisis de la diferencia entre la educación continental y la anglosajona, lo que Bloom llama "the two states of Nature". Allí Bloom acusa a los pensadores occidentales de "have been obsessed with bourgeois man as representing the worst and most contemptible failure of modernity, which must at all costs be overcome", mientras sostiene que los americanos son "lockeanos" en tanto reconocen al trabajo como aquello que produce el bienestar. En este contexto remite a Strauss para afirmar que "the promise of salvation" para los pobres constituiría el elemento moderno sobre el cual se construye el sistema americano.

25 Entre otras las más significativas: M. Nussbaum, "Undemocratic Vistas", en New York Review of Books 34, no. 17, November 5, 1987. <http://www.nybooks.com/articles/1987/11/05/undemocratic-vistas/>, ver la retrospectiva de A. Ferguson, "The Book That Drove Them Crazy", The Weekly Standard (April 9, 2012). <http:// www.weeklystandard.com/book-drove-them-crazy/article/634905?nopager=1>.

26 Cf. G. A. Almond, "Separate tables: Schools and sects in political science", Political Science and Politics, 4/21, 1988, pp. 828-842.

27 Cf. S. Drury, "The Esoteric Philosophy of Leo Strauss", Political Theory 13 (3), 1985, pp. 315-337.

28 Esto sería desarrollado luego en S. Drury, The Political Ideas of Leo Strauss, New York, St. Martin's Press, 1988, el cual junto con el artículo de 1985 constituye un texto seminal sobre esta cuestión.

29 L. Strauss, Persecution and the Art of Writing, Glencoe, The Free Press, 1952. 
de Strauss el contexto en el que éste desarrolla su pensamiento: un conservador extremo que se desenvuelve en un mundo democrático.

\subsection{La "filosofía política platónica": la construcción de una tradición}

Leo Strauss dedica gran parte de sus escritos al estudio del pensamiento de Platón considerando sus propias obras como "estudios de filosofía política platónica" 30 . No obstante, dicho proyecto es mucho más ambicioso que el de comentar las obras del filósofo ateniense, en tanto busca elaborar una nueva filosofía política de base platónica. Para ello, su platonismo se asienta en una tradición mucho más amplia, la cual el propio trabajo histórico-filosófico de Strauss trató de definir. En este sentido, él mismo define al "platonismo" de dicha tradición en un artículo de 1945:

A los platónicos no les interesa la verdad histórica (accidental), ya que están interesados exclusivamente en la verdad filosófica (esencial). Solo porque el discurso público exige una mezcla de seriedad y alegría, un verdadero platónico puede presentar la enseñanza seria, la enseñanza filosófica, en un atuendo histórico, y, por lo tanto, juguetón ${ }^{31}$.

Nótese en esta caracterización un elemento clave en la lectura que realiza de Platón: la referencia a la oposición entre "lo serio" (the serious) y "lo lúdico" (the

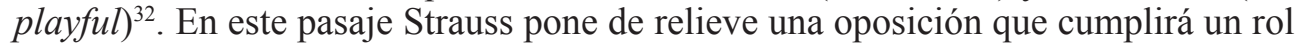
central en su interpretación del pensamiento de Platón, esto es, que la mezcla entre lo lúdico y lo serio corresponde al "discurso (en) público" y sólo de esa manera el filósofo puede enseñar seriamente la verdad. En su comentario al libro III de Leyes Strauss sostiene que para Platón "la sabiduría debe convertirse en el ingrediente de una mezcla" ${ }^{33}$, siendo la mezcla lo que le permite al sabio poder gobernar de manera justa. Por esta razón, afirma Strauss, "el imperio de la ley es un tipo de gobierno de los más fuertes, mientras que el de la sabiduría no lo es" ${ }^{34}$. Puesto que "lo (puramente) serio" no puede ser dicho en público, porque la verdad filosófica no es accesible a todos. Pero "lo (puramente) lúdico" tampoco, ya que ello nos haría caer en la "verdadera mentira" (hos alethôs psêudos) ${ }^{35}$, esto es, "la ignorancia en el alma de quien

30 Tal es el título otorgado a una recopilación de ensayos que tenía prevista y que no llegó a publicar en vida, la cual fue publicada póstumamente por su discípulo y albacea literario Joseph Cropsey. En ella se reúnen artículos, ensayos y reseñas sobre diversos autores que le permiten a Strauss reconstruir lo que él considera la “tradición platónica”. Sobre esta cuestión ver el libro: L. Strauss, Studies in Platonic Political Philosophy, op. cit.

31 L. Strauss, "Farabi’s Plato", en Louis Ginzberg Jubilee Volume, New York, American Academy for Jewish Research, 1945, pp. 376-377.

32 Esta oposición es una constante en muchos de los diálogos platónicos, por ejemplo, en Fedro (227c-228e; 237b2-6) y en Carta VII 343a1. Sobre la cuestión del juego y lo serio, ver: E. Guzmán Mesa, "El juego y lo serio en los diálogos de Platón", en Revista Estudios de Filosofia 2, 1990, pp. 25-34. Para un análisis de esta oposición en clave política, cf. S. Barrionuevo, "La praxis filosófica como praxis política. Una lectura de «lo político» en el Fedro de Platón”, en Praxis Filosófica 41 (2016), pp. 73-76.

33 L. Strauss, The Argument and the Action of Plato's "Laws", op. cit., p. 47.

34 Ibidem (trad. propia).

35 Pl. Rp. 382a4-5; trad. C. Eggers Lan: Platón, República, Madrid, Gredos, 2000. 
está engañado" (he en tê psuchê ágnoia he toû epseusménou) ${ }^{36}$. Por esta razón, los guardianes (phúlakas) de la politeía (ideal), es decir, "quienes cuiden que los enemigos de afuera no puedan hacer mal ni los amigos de adentro deseen hacerlo" (tôn te éxothen polemion tôn te entòs philion, hópos hoy mèn mè boulésontai) $)^{37}$, tienen que inventar "mentiras nobles" (gennaia pseudea). Estas tiene como objetivo persuadir tanto a los gobernantes como a los demás ciudadanos ${ }^{38}$, garantizando así el "gobierno secreto" de los sabios y, por ende, el funcionamiento "justo" de la pólis.

Strauss, por tanto, deriva de aquí una enseñanza que define su adscripción al "platonismo": la filosofía política es la forma política del filosofar. De modo que, su proyecto filosófico consiste en recuperar este objetivo político para la filosofía. Para ello, propone una rehabilitación de la filosofía política clásica por sobre el tecnicismo cientificista en el que la modernidad la habría subsumido. La "ciencia política" como producto de la modernidad se presenta así como la forma en que el pensamiento liberal oculta "lo político" de manera "extraordinariamente lógica" (erstaunlich konsequente $)^{39}$. Ello se debe a que ésta, bajo el manto de un discurso científico-técnico que garantiza la neutralidad objetiva, busca erradicar la valoración moral de los regímenes políticos. En este sentido, sostiene Meier ${ }^{40}$, Strauss en su primer libro titulado Philosophie und Gesetz (1935) ya definía su proyecto filosófico como una oposición a los tratados teológico-políticos del siglo XVII ${ }^{41}$.

\subsection{Esoterismo}

Shadia Drury argumenta la enseñanza que Strauss toma de Platón consiste en reconocer el orden natural de la desigualdad, la necesidad de la mentira por parte de los gobernantes y el gobierno encubierto de los sabios ${ }^{42}$. Por ello, para la filósofa canadiense, la "lectura esotérica" que Strauss realiza de la historia de la filosofía política, en general, y de Platón, en particular, responde más a una posición filosófica que a un principio hermenéutico ${ }^{43}$. De manera que en la lectura Straussiana la "política del mito" elaborada por Platón ${ }^{44}$ se ve reconfigurada bajo la forma de la "doctrina esotérica". Strauss establece una distinción en la doctrina platónica colocando en un

Ibidem 382b8-9.

Ibidem 414b2-3.

Cf. ibidem $414 \mathrm{~b}-\mathrm{c}$.

39 L. Strauss, "Anmerkungen zu Carl Schmitt, Der Begriff des Politischen" [1932], en H. Meier, Carl Schmitt, Leo Strauss und "Der Begriff des Politischen", Stuttgart, Verlag J. B. Metzler, 2013, p. 101 (trad. española: "Comentario sobre El concepto de lo político", en H. Meier, Carl Schmitt, Leo Strauss y El concepto de lo político: un diálogo entre ausentes, Buenos Aires, Katz, 2008, p. 136).

40 H. Meier, Leo Strauss y el problema teológico-politico, Buenos Aires, Katz, 2006, p. 46-48.

41 Strauss considera que la crítica radical del concepto moderno de "cultura" solo sería posible bajo la forma de un "tratado teológico-político" que "si no ha de conducir nuevamente a la fundamentación de la cultura, [adquiera al menos] la tendencia exactamente opuesta de los tratados teológico-políticos del siglo XVII, en particular los de Hobbes y Spinoza" (L. Strauss, Philosophie und Gesetz, en Gesammelte Schriften, Bd. 2 Stuttgart: Metzler, 1997, pp. 30-31, n. 2, citado en H. Meier, Leo Strauss y el problema teológico-político, op. cit., p. 47).

42 Cf. Drury, S. (2003): "Noble lies and perpetual war: Leo Strauss, the neocons, and Iraq", en Open Democracy. Free Thinking for the World, 16 October, 2003 [online] <https://www.opendemocracy.net/faith-iraqwarphiloshophy/article_1542.jsp>

43 Cf. S. Drury, "The Esoteric Philosophy of Leo Strauss", en Political Theory 13 (3), 1985, pp. 315-316.

44 Cf. N. Loraux, Nacido de la tierra. Mito y política en Atenas, Buenos Aires, El cuenco de plata, 2007, pp. 47-49. 
lado la exotérica que se refiere a lo que Platón escribió y comunicaba públicamente, mientras que, por otra parte, tendría una esotérica que sería lo que éste realmente quería transmitir, su proyecto político reservado exclusivamente a "los sabios". En consecuencia, la "política del mito" pondría en evidencia que para Platón el filósofo guarda una verdad, la filosófica, que no es accesible a todos y que éste transmite (parcialmente) mediante discursos que versan entre lo serio y lo lúdico ${ }^{45}$. De modo que, dichos discursos cumplen la función de "mentira noble", encubriendo así la verdad que el filósofo conoce por tener acceso directo a ella. Sin embargo, Strauss interpreta esta práctica de escritura en clave nietzscheana. Considera que ello se debe a que Platón consideraría poco conveniente exponer al público a las "verdades terribles" (erschreckliche Wahrheiten $)^{46}$, puesto que los proyectos que se proponen en cierta medida los excluyen.

En este sentido, Strauss lee en la Calípolis platónica una sátira del "idealismo político". Así, el filósofo ateniense, por medio de esta sátira, busca convencernos de que este tipo de ciudad es inviable y que, por tanto, el filósofo no puede ni debe gobernar directamente ${ }^{47}$. Es decir, para Strauss, la República es un libro irónico cuya intención es mostrar la incompatibilidad entre el filósofo y la ciudad ${ }^{48}$. Por este motivo, el "gobierno secreto de los sabios" no es presentado como una consecuencia de las injusticias de la pólis para con el filósofo, sino más bien como condición para que la pólis pueda realizar la "justicia". El esoterismo no es leído como una "enfermedad" de la pólis, es decir un mal que debe ser erradicado, sino, por el contrario, como condición para el funcionamiento "sano" del Estado.

\subsection{La decadencia de Occidente y el liberalismo}

El "platonismo straussiano" se encuadra en la recuperación del pensamiento político platónico, aunque en el marco de una nueva lógica y un nuevo lenguaje. Por esta razón, el esfuerzo de Strauss consiste fundamentalmente en traducir los conceptos platónicos a un nuevo lenguaje y hacerlos operar también en una nueva lógica ${ }^{49}$. Por un lado, una lógica que opera en el marco de la consolidación del imperialismo capitalista; mientras que, por otro lado, un lenguaje en el que los términos del platonismo necesitan ser reconceptualizados. En el contexto intelectual del pensamiento platónico, éste disputa los espacios de poder simbólico con el relativismo sofístico enmarcados en la lógica de la democracia ateniense. Sin embargo, éste "relativismo" es traducido, en el pensamiento de Strauss, bajo la figura del "nihilismo", el cual

45 Cf. L. Strauss, "Farabi’s Plato", op. cit., pp. 376-377

46 "wir sind hier auf einem Gebiete, wo es so viel Wahrheiten zu sagen giebt, so viel erschreckliche peinliche unverzeihliche Wahrheiten, daß der aufrichtigste Haß uns nicht fehlen wird, und nur die Wuth es hier und da einmal zu einem verlegnen Lachen bringen möchte" (F. Nietzsche, Ueber die Zukunft unserer Bildungsanstalten. Sechs offentliche Vortrage, en G. Colli \& M. Montinari (eds.), Kritische Studienausgabe, Band 1 (KSA 1), Berlin, De Gruyter, 1988, p. 696).

47 Cf. L. Strauss The City and Man, op. cit., pp. 122-138.

48 Cf. P. López Barja, "Leo Strauss y la antigüedad neocon”, en L. Sancho Rocher (ed.), La antigüedad como paradigma: espejismos, mitos y silencios en el uso de la historia del mundo clásico por los modernos, Zaragoza, Prensas de la Universidad de Zaragoza, 2015, p. 194.

49 Cf. E. J. Palti, “The «Theoretical Revolution» in Intellectual History: From the History of Political Ideas to the History of Political Languages", en History and Theory 53, 2014, pp. 400-405. DOI:10.1111/hith.10719. 
es un indicio de la "decadencia de Occidente" representada por la "democracia liberal".

El tema de "la decadencia de Occidente" es una de las principales cuestiones abordadas por Strauss, la cual, como había sostenido Carl Schmitt, define la condición existencial del siglo $\mathrm{XX}^{50}$. El estudio de los clásicos de la filosofía política moderna le permite establecer una línea de continuidad con dicha decadencia, anunciada en éstos autores bajo la forma del "despotismo oriental" 51 . Sin embargo, para Strauss, los tratados teológico-políticos del siglo XVII y la Ilustración son los que habrían corrompido de modo irrecuperable la tradición Occidental, en tanto pusieron a la razón por sobre la tradición o la fe revelada ${ }^{52}$. El fracaso del proyecto moderno, para Strauss, consistiría en que no lograron demostrar la superioridad de la alternativa moderna, sino que sólo se vieron limitados a contrarrestar el peligro político de la religión desplazándola al ámbito de lo privado. El liberalismo, de esta forma para él, niega el carácter conflictivo de "lo político", expresado en posiciones reveladas irreconciliables, al tratar de neutralizarlo. Los tratados teológico-políticos del siglo XVII al recluir el litigio religioso a la esfera privada - es decir, del individuo_-, elimina la conflictividad mediante la afirmación del pluralismo de valores. En este punto, el diagnóstico de Strauss coincide con el de Schmitt, el liberalismo moderno y, por ende, el pluralismo de los valores establece el punto de partida del fracaso del proyecto moderno en la fundamentación del Estado y la decadencia de Occidente ${ }^{53}$.

El liberalismo, para Strauss, es uno de los principales indicadores de la decadencia de Occidente, en tanto la noción de "igualdad natural" expande el egoísmo individualista. En este sentido comparte la lectura que Macpherson realiza de la teoría política liberal ${ }^{54}$. En su libro Macpherson sostiene que la teoría política liberal se encuentra en crisis y ésta no puede superarse retornando a los teóricos clásicos de la democracia liberal, porque padecen del mismo defecto fundamental: el individualismo posesivo ${ }^{55}$. No obstante, Strauss critica a éste el no haber demostrado, además, que esta doctrina es favorable a la sociedad posesiva de mercado, debido a que busca persuadirnos de que éste tipo de organización social es el más conducente para el bienestar humano ${ }^{56}$. Por esta razón, considera que gran parte de la "Ciencia política contemporánea" no sólo es incapaz de analizar la democracia moderna, sino que, además, al reproducir los valores liberales refuerza los peligros que se derivan de éstos:

Al enseñar, en efecto, la igualdad de literalmente todos los deseos, enseña que no hay nada de lo que un hombre deba avergonzarse; al destruir la posibilidad del deseo de sí, destruye, con la mejor de las intenciones, la posibilidad del respeto de sí. Al enseñar la igualdad de todos los valores, al negar la existencia de cosas que

\footnotetext{
L. Strauss, “Anmerkungen...”, op. cit., p. 100.

L. Strauss \& A. Kojève, On tyranny, op.c it., p. 3.

52 Cf. D. Tanguy, Leo Strauss. A Intellectual Biography, New Haven and London, Yale University Press, 2007, p. 31.

53 Cf. H. Meier, Leo Strauss y el problema teológico-político, op. cit., p. 33-88.

54 Cf. C. B. Macpherson, The Political Theory of Possessive Individualism: Hobbes to Locke, Oxford and New York, Oxford University Press, 1962.

55 Cf. ibidem, pp. 263-277.

56 Cf. L. Strauss, "Review of C.B. Macpherson, The Political Theory of Possessive Individualism: Hobbes to Locke", en Studies in Platonic Political Philosophy, op. cit., p. 230.
} 
son intrínsecamente elevadas y de otras que son intrínsecamente bajas, así como al negar que exista una diferencia esencial entre los hombres y los brutos, sin ser consciente de ello contribuye a la victoria de la abyección ${ }^{57}$.

De modo que el "igualitarismo liberal" y su propensión al "individualismo posesivo" conllevan, para Strauss, a la crisis de la sociedad contemporánea, en tanto promueven el conflicto y la desintegración social. Para Strauss el liberalismo, por tanto, al establecer la igualdad como punto de partida en la realización de los deseos desarticula los valores que dan unidad y cohesión a la sociedad, en tanto no hay criterios de demarcación entre "lo bueno" y "lo malo". Por ello, según este planteo, la "política platónica del mito" debe traducirse modernamente en una política capaz de reconstruir la cohesión social por medio de valores regulados por parte del Estado.

En este punto el antiliberalismo de Strauss coincide con el de Carl Schmitt. Leo Strauss comparte con el jurista que la época actual pone en evidencia el fracaso del liberalismo, de manera que "se toma conciencia de la idea de que el Estado sólo puede ser entendido a partir de la afirmación de lo político" 58 . No obstante, le crítica a éste el considerar que ello se resuelve con un retorno a Hobbes: "lo que Schmitt destaca como lo fundamentalmente político es el «estado de naturaleza» que subyace a toda cultura" ${ }^{\prime 2}$. Sin embargo, concluye que la idea de un status naturalis como status belii por antonomasia cumple funciones distintas en el contexto en que cada uno lo plantea: "Hobbes sienta las bases del liberalismo en un mundo no liberal, en un mundo liberal Schmitt emprende la crítica del liberalismo" ${ }^{60}$. Aunque, para Strauss, esto no es suficiente, dado que implica colocar nuevamente al individuo en el centro de la teoría política, y, por tanto, Schmitt "queda preso en el campo delimitado por el liberalismo" $"$. Pero esto, considera, no es casual, sino una consecuencia necesaria, ya que infringe su propio principio: "comprender todos los conceptos de la esfera espiritual [...] a partir de la existencia política concreta" ${ }^{2}$. Por esta razón, la vuelta a Platón y los filósofos clásicos implicaría, para Strauss, una restitución de la comunidad política. En este sentido Sergio Morresi sostiene que para Strauss:

dado que la fuente de la decadencia occidental ha sido ubicada en el origen mismo de la modernidad, las respuestas deben ser buscadas en un punto anterior a su llegada. Es decir, si la decadencia de Occidente comenzó con Maquiavelo, con Hobbes y -sobre todo- con Spinoza, quien quisiera resolver la cuestión debería retroceder hasta sus maestros ${ }^{63}$.

Para Morresi, el intento de suturar la fractura abierta por la querella entre los antiguos y los modernos para salvar a Occidente de su propio derrumbe, por tanto, derivaría en una "redención clásica del mundo moderno", esto es, una suerte de elitismo en el cual sólo unos pocos pueden llevar a cabo dicha tarea. Sin embargo, si bien esto implica dejar de lado el modelo de "democracia liberal" como forma de la

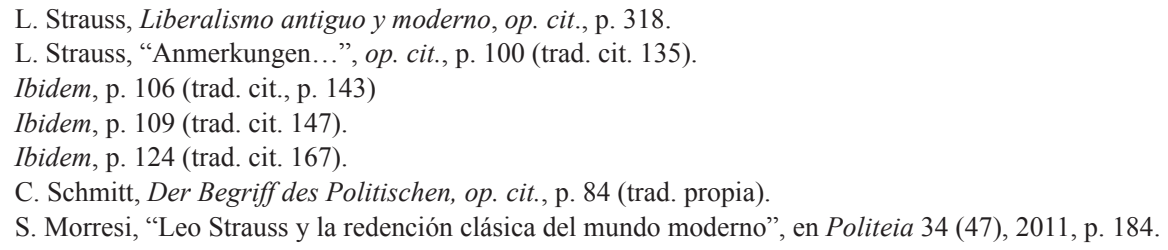


"democracia moderna", no presupone dejar de lado la "modernidad democrática", esto es la democracia como competencia entre élites dirigentes. Sino que, la restitución de los antiguos, antes que constituir una experiencia melancólica de retorno a la antigüedad, se presenta como una estrategia de recuperación de su "esencia" para la realización del destino histórico de Occidente.

\section{La construcción del mito imperialista: EIneoconservadurismo norteamericano}

En el marco de la política norteamericana los neoconservadores no constituyen exclusivamente un conjunto de académicos, sino más bien un grupo de intelectuales que por su condición intervienen en el espacio público. Su trabajo intelectual se caracteriza por llevar a cabo, en muchas ocasiones, un proceso de trasposición de algunas ideas políticas de Strauss al plano de la práctica política. En este sentido, sostiene López Barja, éstos podrían asimilarse a los oradores áticos cuya función consistía en convertir en directrices políticas las ideas abstractas que no podían tener una plasmación directa en la vida real. Tal es así que, muchos de los miembros de ésta "persuasión" política formaron parte de los gabinetes de distintas administraciones del gobierno norteamericano. ${ }^{64}$ Por este motivo, en esta sección analizo los alcances de la recepción del "platonismo straussiano" en la conformación del neoconservadurismo y evalúo el rol que ella cumple en la legitimación discursiva de la política internacional norteamericana.

\subsection{Neoconservadores}

Los neoconservadores se originan hacia la década de los sesenta en el "City College of New York", también conocido como "el Harvard de los pobres", donde se reunieron un grupo de estudiantes de origen humilde, hijos de judíos de Europa del Este y emigrados hacia Estados Unidos a fines del siglo XIX, los cuales compartían ideas troskistas. En esta sala se reunían: Irving Kristol (1920-2009), Daniel Bell (19192011), Nathan Glazer (1923) e Irving Howe (1920-1993), quienes fueron llamados de manera despectiva "neoconservadores" — luego abreviado "neocon" — por Michael Harrington ${ }^{65}$. Este grupo se articula en torno a la crítica marxista al capitalismo, el rechazo del estalinismo y, por consiguiente, el mantenimiento de una posición fuerte frente a la Unión Soviética. Tal es así que Irving Kristol, considerado "el padre fundador del neoconservadurismo", antepone la lucha contra el comunismo a la defensa de los derechos civiles ${ }^{66}$.

El neoconservadurismo, según Brown:

${ }_{64}$ Cf. P. López Barja, "Leo Strauss y la antigüedad neocon”, op. cit., p. 194.

65 Cf. I. Kristol, Neoconservatism. The Autobiography of an Idea (Selected Essays 1949-1995), New York, Free Press, 1995, p. 33.

${ }^{66}$ Cf. I. Kristol, “"Civil Liberties», 1952 - A Study in Confusion: Do We Defend Our Rights by Protecting Communists?”, en Commentary, March 1, 1952, pp. 228-236 < https:/www.commentarymagazine.com/articles/ civil-liberties-1952-a-study-in-confusiondo-we-defend-our-rights-by-protecting-communists/>, y "Liberty and the Communists", en Partisan Review, July-August, 1952, pp. 493-496. Cf. P. López Barja, "Leo Strauss y la antigüedad neocon", op. cit., p. 188. 
surge de una convergencia contingente de intereses entre los cristianos evangélicos, los judíos straussianos, los partidarios de la Guerra Fría que han hecho un fetiche de Occidente, las feministas conservadoras y otros moralistas, los imperialistas aleatorios y los liberales y socialistas convertidos que, según las palabras infames de Irving Kristol, han sido "asaltados por la realidad" 67.

No obstante, esta heterogeneidad se explica, en palabras de Marvin Meyers retomadas luego por Irving Kristol ${ }^{68}$, porque constituye una "persuasión" antes que un "movimiento". Esto es, una manera de pensar la política, la cual, según Fukuyama, se rige por la creencia en que "el poder estadounidense ha sido y podría ser usado para propósitos morales" ${ }^{2}$. Esta premisa habría otorgado en la lógica mesiánica del "neconservadurismo" un destino moral inevitable al gobierno norteamericano. Este destino, según Hanson y Heath, proviene históricamente de la "herencia griega" del imperialismo norteamericano:

Incluso el crítico académico más acérrimo de Occidente preferiría volar en Swissair, registrarse en la Clínica Mayo, gritar obscenidades en Times Square, pasar una luz roja en Omaha, nadar con su novia en la playa de Santa Cruz o vivir al lado de una base del ejército de los EE. UU. en Texas antes que abordar un avión de pasajeros congoleño, deje su apéndice en Managua, use el nombre de Allah en vano en el centro de Jeddah, salte de la acera en Singapur, use un bikini y un bañador de Speedos en Irán, o vacacione cerca de la casa de la Guardia Nacional de Corea . ¿Por qué? Los griegos ${ }^{70}$.

Por esta razón, el "helenismo norteamericano" de los neoconservadores es leído, en la clave del "platonismo straussiano", como caracterización de los valores occidentales. De manera que, para estos, la defensa de los valores de Occidente pasa a formar parte del "trabajo del mito" que el Estado debe realizar para garantizar la cohesión social, en el cual el nacionalismo constituye uno de los elementos centrales para su mantenimiento en el tiempo. Para ello, resulta necesaria por parte de éstos, en tanto intelectuales orgánicos funcionales al stablishment de Occidente, una acción política capaz de intervenir en la opinión pública que cumpla dicho rol "mitificador" entre la ciudadanía norteamericana.

\subsection{Acción política}

Los neoconservadores asumen al periodismo como forma de expresión y como mecanismo de intervención en el espacio público. Principalmente en aquellas revistas que fueron fundadas por miembros de este grupo (The Public Interest, fundada por

${ }^{67}$ W. Brown, "American Nightmare. Neoliberalism, Neoconservatism and De-Democratization", en Political Theory 34 (6), 2006, p. 696.

68 Cf. I. Kristol, "The Neoconservative Persuasion", en The Weekly Standard, 25 August, 2003. [online] <http:// www.weeklystandard.com/the-neoconservative-persuasion/article/4246>.

69 F. Fukuyama, America at the Crossroads. Democracy, Power, and the Neoconservative Legacy, New Haven \& London, Yale University Press, 2006, p. 48.

70 V.D. Hanson \& J. Heath, Who Killed Homer? The Demise of Classical Education and the Recovery of Greek Wisdom, New York, The Free Press, 1998, p. 56. 
Daniel Bell e Irving Kristol en 1965; The National Interest, fundada también por Kristol en 1985; Weekly Standard, fundada en 1995 y que tiene como editores a W. Kristol y F. Barnes) o publicaciones de larga tradición dirigidas por ellos (Commentary, dirigida por N. Podhoretz y luego por su hijo John). Por ello, una parte de su acción política deriva de sus formas de intervención en la opinión pública.

Sin embargo, desde la administración Reagan (1981-89), los "neocon" adquieren una mayor influencia en el gobierno debido a una difícil alianza con republicanos tradicionales y neoliberales. Principalmente uno de los mayores puntos de tensión versa en torno al lugar que le otorgan al Estado y la religión. Para los "necon" el primero debe regular los excesos del capitalismo y el segundo debe cumplir un rol central en la conformación de la cohesión social. Asimismo, hacia mediados de los noventa su principal medio de intervención política lo constituyen los think-tank o "investigadores en política pública". Esto es, un grupo de expertos cuya función es la reflexión intelectual acerca de asuntos de política pública con el fin de fomentar decisiones informadas, quienes pueden estar afiliados con partidos políticos, gobiernos, corporaciones u organizaciones no gubernamentales ${ }^{71}$. Si bien este tipo de organizaciones de intelectuales tiene presencia en la política norteamericana desde comienzos del siglo XX (las primeras fueron la Russell Sage Foundation y la Bureau of Municipal Research, ambas fundadas en 1907), a partir de la década de los sesenta, en el marco de un nuevo contexto ideológico, éstos adquieren una función político-ideológica que va a ser definida por los diferentes actores ${ }^{72}$. En dicho marco de reformulación de la función de las think-tank los neoconservadores habían fundado sus revistas. Hacia la década del noventa éstos ponen en marcha el Project for the New American Century (1997-2006), entre los que se cuentan figuras claves del movimiento como William Kristol y Robert Kagan, así como personas importantes en la administración de George W. Bush como Dick Cheney (vicepresidente), Donal Rumsfeld (secretario de defensa) y Paul Wolfowitz (segundo secretario de defensa). En este período el American Enterprise Institute también se alinea con los postulados neconservadores y en 2001 se conforma también la Foundation for Defence of Democracy, fundada en 2001 por Clifford May.

Los "neocon" tuvieron impacto en la política norteamericana por medio de sus intervenciones en la esfera pública, a través de su participación en medios gráficos o audiovisuales en tanto miembros de las think-tank. Pero, adquieren mayor impacto por su participación directa en la administración del Estado. Tal es así que William Kistrol llegó a formar parte del gabinete de Dan Quayle (vicepresidente durante el mandato de George H. W. Bush), así como también debe tenerse en cuenta la influencia de Victor Hanson sobre Dick Cheney (vicepresidente de la administración George W. Bush) ${ }^{73}$.

Los neoconservadores, por tanto, no son un grupo de intelectuales recluidos en el mundo académico, sino que, por el contrario, se constituyen como agentes de

71 Cf. J. G. McGann, Think Tanks and Policy Advice in the United States Academics, advisors and advocates, New York, Routledge, 2007, pp. 11-35.

72 Cf. A. Rich, Think Tanks, Public Policy, and the Politics of Expertise, Cambridge, Cambridge University Press, 2004, pp. 29-73.

73 Cf. J. Ehrman, The Rise of Neoconservatism: Intellectuals and Foreign Affairs, 1945-1994, New Haven, Yale University Press, 1996, p. 192; J. H. Lane, "Thucydides Beyond the Cold War: The Recurrence of Relevance in the Classical Historians", Poroi: An Interdisciplinary Journal of Rhetorical Analysis and Invention 4/2 (2005), pp. 55. DOI: 10.13008/2151-2957.1024. 
enunciación en el espacio público y como actores políticos en la administración gubernamental. En este sentido, sostiene Rich, los miembros de las think-tank actúan como agentes ideológicos antes que como analistas independientes, en tanto defienden visiones particulares de políticas públicas en lugar de informar el debate desde la investigación ${ }^{74}$.

\subsection{Diagnóstico}

En la década de los sesenta tras el fracaso del proyecto "The Great Society" del gobierno de Lyndon B. Johnson, miembro del partido demócrata, Irving Kristol, prominente militante de la izquierda troskista norteamericana, comenzó a plantear que fue la sociedad liberal y la expansión del espíritu individualista la causa de dicho fracaso. Estos diagnósticos encontraron su apoyatura teórica en las ideas de Leo Strauss y su propuesta de una "filosofía política platónica", dando lugar a la "persuasión" de que es la decadencia de la "sociedad liberal" la que explica al fracaso del proyecto moderno. Esta premisa constituye el núcleo duro del "neoconservadurismo" formulado por Irving Kristol y el grupo de intelectuales vinculados a él (Paul Wolfowitz, Francis Fukuyama, su hijo William Kristol, etc.). Los elementos de la "sociedad liberal" a los que se oponen los "neconservadores" exigen por parte de éstos una re-traducción de los conceptos straussianos, tal como lo había hecho éste último con el pensamiento platónico. En este sentido, Irving Kristol reconoce en la "contracultura" los aspectos más relevantes de la decadencia de la "sociedad liberal" como expresión "moderna" del nihilismo ${ }^{75}$. Ésta, según su perspectiva, atenta contra la cohesión social, dado que "las contraculturas son fenómenos peligrosos aun cuando son inevitables. Su poder destructivo siempre supera con creces su poder

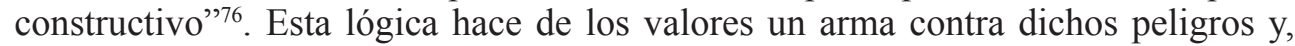
dentro de esta concepción, es el Estado quien debe combatirlo desde la reafirmación de los mismos.

Allan Bloom, en su influyente y seminal libro The Closing of the American Mind (1988), traducía el diagnóstico de la "decadencia de Occidente" straussiana para el caso americano. Allí definía a los movimientos estudiantiles de la década de los sesenta como el golpe mortal a la tradición universitaria norteamericana, originado por la importación de las modas intelectuales parisinas ${ }^{77}$. Tal es así que en un apartado dedicado a "la descomposición de la Universidad americana" sostiene que, en el caso de la Universidad de Cornell, las causas de su descomposición fueron que "durante varios años ha habido una operación de lavado de cabeza por parte de las ideas radicales de la izquierda francesa en literatura comparada. Desde Sartre, pasando por Goldmann, hasta Foucault y Derrida"78. Éstos, a juicio de Bloom, incorporaron ejercicios de auto-satisfacción igualitaria que rechazan todo tipo de fundamentación

74 Cf. A. Rich, Think Tanks..., op. cit., pp. 210-215.

75 "The fact is that the counterculture was not "caused," it was born. What happened was internal to our culture and society, not external to it" (I. Kristol, "Countercultures”, Commentary Magazine, December 1, 1994, [online] < https://www.commentarymagazine.com/articles/countercultures/>).

76 "Countercultures are dangerous phenomena even as they are inevitable. Their destructive power always far exceeds their constructive power", ibidem (trad. propia)

77 Cf. A. Bloom, The Closing of the American Mind, op. cit., p. 320.

78 Ibidem, p. 352 (trad. propia). 
racional de los juicios morales. Esta situación, de acuerdo con Kristol, equipara al "multiculturalismo" de los radicales de izquierda con una "guerra contra Occidente". Ello se debe a que amenazan con disolver los fundamentos éticos de la nación al atacar la supremacía de Occidente, encarnada ahora en el imperialismo norteamericano $^{79}$.

El "multiculturalismo" en el contexto norteamericano, por tanto, representa para los neoconservadores una amenaza similar a la del "liberalismo" para Occidente en el diagnóstico de Strauss. Ello se debe a que ambos "sostienen que ningún modo de vida es preferible en sí mismo, por lo que el Estado debe mantener una posición neutral permitiendo que cada ciudadano viva la vida que él mismo elija" 80 . Sin embargo, la ley natural dicta que hay valores preferibles a otros, los cuales, en el marco de la ideología neocon, estarían encarnados por Estados Unidos, quien tiene, por tanto, la obligación moral de defenderlos. Estos preceptos, a su vez, enmarcados en el contexto de las lógicas geopolíticas del gobierno norteamericano fundamentan, en términos de política internacional, la nueva doctrina de la "guerra justa". Puesto que ella sería expresión de su obligación moral de defender la superioridad de los valores morales de Occidente.

\subsection{Fundamentación de la política internacional}

Los neoconservadores, recuperando el rechazo straussiano a la ciencia política, consideran que los regímenes políticos deben ser evaluados moralmente. De ello se deriva, entonces, la distinción entre regímenes "buenos", los que definen la supremacía de los valores Occidentales, y regímenes "malos", los que atentan contra dichos valores. Por este motivo, se asocian los valores de Occidente con la forma política del régimen que definen el modo de ser de un pueblo ${ }^{81}$.

Los políticos, dentro de esta "lógica straussiana-neocon", no sólo tienen permitido "mentir" en pos de un "bien noble" — como lo es mantener la unidad social del Estado_-, sino que además tienen la obligación moral de hacerlo para combatir al nihilismo. En términos de política internacional e implementación de estrategias geopolíticas, esto se traduce en una justificación del intervencionismo militar por parte de Estados Unidos. No obstante, dicha situación se legitima desde diversos ángulos.

Por un lado, se propone una legitimación filosófica de esta política internacional. En primer lugar, a partir de una aplicación de la "enseñanza platónica" en clave esotérica de Strauss. La "mentira noble" y el gobierno encubierto de los sabios se justifican en tanto estrategias para eliminar el nihilismo como expresión de la decadencia de Occidente. En segundo lugar, dado que Estados Unidos representa los valores Occidentales, su imperialismo no sólo es un régimen válido, como lo propondrían los análisis de la ciencia política, sino además moralmente legítimo, en tanto heredero de los valores de Occidente. Por ello, dentro de esta lógica, la política internacional

Cf. I. Kristol, Neoconservatism, op. cit., p. 52.

P. López Barja, "Leo Strauss y la antigüedad neocon”, op. cit., p. 198.

81 Esta idea straussiana es típicamente griega (Tucídides, Historia de la guerra del Peloponeso II.35-46; Platón, República 368a-369b), aunque adaptada a la época moderna. Sobre este punto ver: L. Strauss, Liberalismo antiguo y moderno [1968], Buenos Aires, Katz, 2007, pp. 306-310. 
de intervención militar norteamericana, no sólo encuentra un punto de legitimación filosófica, sino que además define una acción política concreta partiendo de las responsabilidades morales que ella trae consigo.

Por otra parte, la legitimación filosófica se ve reafirmada a partir de una "legitimación histórica". Donald Kagan, historiador lituano radicado en Estados Unidos y miembro del think-tank neoconservador Project for the New American Century, realiza a fines de la década de los noventa un ensayo de lectura neocon de Tucídides ${ }^{82}$. En este libro donde reflexiona sobre las causas de la guerra, Kagan retoma a Tucídides para sostener que en la tríada timês kaì déous kaì ophelías ("honor, temor e interés") ${ }^{83}$, el historiador ateniense realiza una exaltación de la guerra convirtiéndola en una cuestión puramente de honor. ${ }^{84}$ Esta lectura está en consonancia con la propuesta por Strauss, quien considera que en Tucídides si el "honor", un valor moral superior de Occidente, constituye una razón para mantener un imperio, entonces no podría considerarse injusta una situación histórica en la cual un Estado someta a otros ${ }^{85}$. Ello se debe a que la desigualdad natural de uno respecto de otro torna inevitable que una se convierta en hegemónica o incluso imperial ${ }^{86}$. En este sentido, para Strauss, la superioridad de un régimen imperial radica en su honorabilidad como condición para la realización de un "imperialismo justo":

La justificación última del imperio ateniense no es la compulsión, el temor o el beneficio, sino la gloria eternal - un objetivo al que los atenienses no están obligados, o que el que no están obsesionados, pero al que se han dedicado libre y plenamente ${ }^{87}$.

En términos históricos, por tanto, el imperialismo ateniense viene a corroborar la dominación universal del fuerte sobre el débil ${ }^{88}$. Esta "lectura historiográfica neocon" se ve reforzada, en clave de justificación ideológica de la guerra, por Victor Hanson. ${ }^{89}$ En su libro The Western Way of War (1989) retoma la temática straussiana de la superioridad moral de la guerra por honor. Allí sostiene que, en el caso griego, la guerra por el honor se ve traducida en una transformación de las formas de combate bélico que minimizaba los daños de la guerra. En varios escritos posteriores

82 Este libro es previo a While American Sleeps, escrito en co-autoría con su hijo Federick Kagan, que fue publicado en las vísperas de las elecciones presidenciales del 2000, las cuales terminó ganando G. W. Bush por sobre $\mathrm{Al}$ Gore. Sin embargo, se encuentran discursivamente en sintonía. En While American Sleeps ambos autores realizan una llamada en defensa del incremento del gasto público en políticas de defensa internacional (D. Kagan \& F. W. Kagan, While America Sleeps: Self-Delusion, Military Weakness, and the Threat to Peace Today; New York, St. Martin's Press, 2000). Asimismo, este libro es posterior a sus trabajos sobre Tucídides (Kagan, 1969, 1974, 1981, 1987) que le habrían otorgado una amplia reputación como especialista en el historiador ateniense (D. Kagan, The Outbreak of the Peloponnesian War, Ithaca, Cornell University Press, 1969; The Archidamian War, Ithaca, Cornell University Press, 1974; The Peace of Nicias and the Sicilian Expedition, Ithaca, Cornell University Press, 1981; The Fall of the Athenian Empire, Ithaca, Cornell University Press, 1987).

83 Tuc. I.76.2; trad. A. Guzmán Guerra, Tucídides, Historia de la guerra del Peloponeso, Madrid, Alianza, 2014.

84 Cf. D. Kagan, On the Origins of War and the Preservation of Peace, New York, Anchor Books, 1996, p. 8.

85 Cf. L. Strauss, "Review of C.B. Macpherson...", en Studies in Platonic Political Philosophy, p. 183.

86 Cf. ibidem, p. 239.

$87 \quad$ Ibidem, p. 211.

88 Cf. ibidem, p. 191.

89 Cf. F. J. González García \& P. López Barja de Quiroga, "Neocon Greece: V. D. Hanson’s War on History”, en International Journal of the Classical tradition 19, 2012, pp. 139-144. DOI: 10.1007/s12138-012-0313-4; P. López Barja, "Leo Strauss y la antigüedad neocon", op. cit., p. 204. 
Hanson busca construir una unidad a nivel narrativo en los valores occidentales, representados por el imperialismo militar griego y los Estados Unidos como su heredero moderno. En esos trabajos se propone trazar una línea de continuidad entre, por ejemplo, Epaminondas como ferviente luchador contra la tiranía y defensor de la idea de democracia, tal como Estados Unidos lo hace contra Saddam Hussein en la guerra del Golfo ${ }^{90}$. Así como cuando presenta a Epaminondas como predecesor de la guerra preventiva para justificar la guerra de Irak y la doctrina de Kagan sobre las formas de intervención armada ${ }^{91}$. Sin embargo, Carnage and Culture ${ }^{92}$ representa uno de sus libros más significativos en la construcción de este relato de continuidad y legitimación histórica neocon. Allí establece un estudio y análisis de un conjunto de batallas decisivas que van desde la guerra contra los Persas hasta la guerra de Vietnam, en donde su objetivo consiste en defender y demostrar la superioridad moral de la cultura Occidental. Su tesis principal es que el triunfo de occidente en la era contemporánea, representada por la hegemonía imperialista norteamericana, se debe a su concepción superior de la libertad.

Esta ideología straussiana-neocon, por consiguiente, está en la base de la política internacional desarrollada y aplicada por el Estado norteamericano, tanto durante el gobierno de Bush padre, en la guerra del Golfo, como el de su hijo, durante el conflicto con medio oriente tras el 11-S. De modo que, para los neoconservadores, siguiendo la lógica mesiánica de la tradición en la que se inscribe, la administración Bush tenía un poder militar y una superioridad moral que le atribuyen la obligación de llevar a cabo la pacificación por medio de la fuerza. De modo que la honoralibilidad que moviliza su acción militar inscribe su accionar en el marco de una "guerra justa" y, por tanto, necesaria para salvaguardar los "valores de Occidente" representados por ellos.

\section{Consideraciones finales}

La aplicación de las políticas neoconservadoras, por tanto, si bien tienen una base "platónica" mediada por el pensamiento de Leo Strauss, no restituyen la lógica política en la que se articulan los conceptos platónicos. Asimismo, la aplicación de la filosofía política de Strauss por parte de los "neoconservadores" que formaron parte de la administración Bush, tampoco restituyeron la lógica platónica. Por este motivo, los conceptos utilizados no se refieren a lo mismo, así como tampoco los lenguajes en los cuales se articulan funcionan de la misma manera y le otorgan el mismo sentido. Por esa razón, la rehabilitación straussiana y neoconservadora del platonismo, si bien pretende reconocer su origen e identificación en el pensamiento platónico, el uso de los mismos términos y de razonamientos similares no implica que utilicen el mismo lenguaje ni la misma lógica política.

90 V. D. Hanson, The Soul of Battle. From Ancient Times to the Present Day. How Three Great Liberators Vanquished Tyranny, New York, Anchor Books, 1999, p. 12.

91 Cf. V. D. Hanson, "Epaminondas the Theban and the doctrine of preemptive War", en Hanson, V. D. (ed.), Makers of Ancient Strategy. From the Persian Wars to the Fall of Rome, Princeton and Oxford, Princeton University Press, 2010, pp. 93-117.

92 V. D. Hanson, Carnage and Culture. Landmark Battles in the Rise of Western Power, New York, Anchor Books, 2002 . 
La "filosofía política" de Platón adquiere sentido en el marco de la contraposición con el relativismo sofístico. Mientras que el pensamiento de Strauss lo hace en el marco del liberalismo moderno y los neocon en el contexto del multiculturalismo. Por esta razón, las lecturas contemporáneas que buscan recuperar la filosofía política platónica necesariamente re-conceptualizan su pensamiento y lo inscriben en nuevas lógicas políticas. De suerte que, el diagnóstico elaborado por Popper acerca del pensamiento platónico pierde sentido, en tanto no sería la lógica del pensamiento político de Platón la base del totalitarismo moderno, sino que el totalitarismo se hace platónico al transponerlo en un nuevo lenguaje y hacerlo operar en una nueva lógica. Al traducir el pensamiento platónico al mundo contemporáneo se trata de establecer referentes contemporáneos para sus conceptos. Sin embargo, los conceptos platónicos se constituyen como "conceptos políticos", en tanto se refieren a problemas de su tiempo antes que a objetos conceptualmente imperecederos. Por ese motivo, la introducción del pensamiento platónico en los debates contemporáneos no es una simple rehabilitación en la que se restituyen los conceptos platónicos a partir de nuevos referentes, sino que implica en sí misma una práctica de lectura que desarticula de la lógica política platónica destituyéndola del marco intelectual que la hace funcionar. 